\title{
Risk Factors of Renal Calculi
}

\author{
Shahida Banu Shamsuddeen*, Dr. Rafia Bano*, Dr. Eyad Al Shammari*, \\ Shamaah Huseen Al Enezi \\ *( Department of Clinical Nutrition, College of Applied Medical Science, University of Hail, Saudi Arabia) \\ **(Student, Department of Clinical Nutrition, College of Applied Medical Science, University of Hail, Saudi \\ Arabia)
}

\section{Introduction}

A kidney stone, also known as a renal calculus (from the Latin rēnēs, "kidneys" and calculus, "pebble") is a solid concretion or crystal aggregation formed in the kidneys from dietary minerals in the urine. The condition of having kidney stones is termed nephrolithiasis. Having stones at any location in the urinary tract is referred to as urolithiasis, and the term ureterolithiasis is used to refer to stones located in the ureters. The hallmark of stones that obstruct the ureters or renal pelvis is excruciating, intermittent pain that radiates from the flank to the groin or to the genital area and inner thigh [1]. This particular type of pain, known as renal colic, is often described as one of the strongest pain sensations known [2].

Among the different types of kidney diseases, renal calculi is a common and a major cause of morbidity. The most predominant renal stones are calcium containing. Nearly $75-80 \%$ of renal stones are calcium containing, composed largely of calcium oxalate followed by calcium phosphate. Another $10-15 \%$ are struvite composed of magnesium ammonium and phosphate. $6 \%$ are uric acid stones and $1-2 \%$ are cysteine stones [3].

The history of renal stones dates back to times of Egyptian mummies [4]. They are found in 1\% of all autopsies [5]. The distribution of urolithiasis varies differently across the world. High incidence areas are Scandinavian countries, Mediterrenanian, British Isles, Northern Australia, and central Europe, parts of Malaysia, China, Pakistan, and Western India. In Asia the stone belt has been reported to stretch across Sudan, Saudi Arabia, UAE, Pakistan, India, Myanmar, Thailand, Indonesia and Philippines [6]. In the United States, overall stone prevalence has doubled since the 1964-1972 time period, and appears to have stabilized since the early 1980s $[7,8,9]$. Other countries with documented increases in prevalence include Germany, Spain, and Italy $[10,11,12,13]$. The risk of developing urolithiasis in adults appears to be higher in the western hemisphere (5-9\% in Europe, $12 \%$ in Canada, $13-15 \%$ in the USA) than in the eastern hemisphere $(1-5 \%)$, although the highest risks have been reported in some Asian countries such as Saudi Arabia (20.1\%) $[14,15]$.

\subsection{Risk Factors}

Risk factors do not have a direct cause of the disease, but some way or the other it is associated with it. Many literatures and studies proves that there is no exact cause of urinary calculi but there are a number of genetic body reaction to certain metabolic and chemical conditions and life style risks that contribute to renal calculi formation $[16,17,18]$.

The common risk factors are age, sex, climate, season, stress, fluid intake, occupation, affluence, diet, genetic and metabolic changes [19]. Diabetic and Hypertension were the other risk factors closely associated with renal calculi in the study population. In Saudi Arabia, the prevalence of diabetes is estimated to be $25 \%$ and the incidence $45 \%$ [20]. Similar high prevalence rates have been reported from a number of Arab countries. For example, prevalence rates for diabetes were reported as high as $46.8 \%$ in Lebanon [21], 21.2\% in Kuwait [22], and $35 \%$ in Egypt [23].

Obesity is known to predispose to insulin resistance and diabetes. Kidney stones were more common among obese individuals than among normal-weight subjects (11.3\% vs. 6.1\%). The reported prevalence of obesity among school children in Riyadh, the capital city of the Kingdom of Saudi Arabia (KSA) is reaching $18 \%$ [24]. Similar high prevalence rates are expected to be found in other countries of the region that have social and cultural backgrounds in common. According to a report published in 1999, at least one third of the Arab population can be categorized as obese [25]. Compared with normal-weight individuals, obese respondents had a $55 \%$ increased risk of kidney stones. The main aim of this study was to identify the most common risk factors which may cause renal calculi and examine if there is a significant relation between those factors and renal stone formation. 


\section{OBJECTIVES}

The following were the objectives of the study

1. To determine the demographic and social profile of patients with renal calculi in Hail city of Saudi Arabia.

2. To analyse the common risk factors in patients with renal calculi.

3. To examine the relationship between the fluid intake and the risk of urinary infections in the subject.

\section{Methodology:}

Hail city.

A cross sectional survey was planned to examine the associated risk factors of renal calculi patients of

\subsection{Design and Sample}

The study was designed as a cross-sectional survey conducted in Hail city during the winter 2012 -13 semester. Patients visiting King Khalid Hospital of Hail City of Saudi nationality suffering from renal calculi during the months of November to December, 2012 were included in this study. The sample size was 50 of both males $(n=25)$ and females $(n=25)$ between the age group of $16 y r s$ to $90 y r s$ for the study. All questions were administered to the subjects to provide the information on their medical history of renal calculi and its associated risk factors. The sample chosen was from all socioeconomic levels.

\subsection{Data Collection}

Data was gathered by interview technique method on a valid questionnaire and anthropometric measurements were also used for data collection. Prior to filling out the questionnaire, the subjects were informed about the study and were given instructions on how to fill out the questionnaire completely and truthfully. Data collection was done on a standardized survey questionnaire with information related to demographic and socioeconomic details, physical activity, sign and symptoms of renal calculi, fluid intake and other related diseases increasing the severity of renal calculi.

In order to determine that obesity is a prominent risk factor of renal calculi anthropometric measurements weight and height were collected using the standard procedures from the sample. Body Mass Index(BMI) was calculated according to the formula (weight $(\mathrm{kg}) /$ height $^{2}(\mathrm{mt})$ ) [26]. According to World Health Organization (WHO), 2004, [27] weight status was classified into four categories: underweight (BMI $\leq$ 18.5), normal weight (BMI between 18.5 - 24.9), overweight (BMI between 25-29.9), and obese (BMI $\geq 30$ ).

\subsection{Validation of the Questionnaire}

For content validity (back to back translation), the questionnaire was initially translated into Arabic and then converted back to English and pre-tested for question accuracy and clarity.

\subsection{Data Analysis}

The data set was cleaned and edited for inconsistencies. Missing data were not statistically computed. Statistical analyses were performed using the Statistical Package for Social Sciences (version 16.0, SPSS, Inc) software. Descriptive statistics such as means and standard deviations were calculated for the continuous variables and frequencies for qualitative data. Associations were established using chi-square analysis. All reported $P$ values were made on the basis of 2 -sided tests and compared to a significance level of $5 \%$; differences were considered statistically significant at $\mathrm{P}<0.05$ or $\mathrm{P}<0.01$.

\section{Results}

A total of 50 patients suffering from renal calculi were analysed. Out of them both males and females were in the ratio 1:1. Age of the sample ranged from 16 to 90 years. The mean age was 42.20 with SD 19.41 yr. The study population had a total mean age $\pm \mathrm{SD}$ was $42.20 \pm 19.41$ years (range 16-90) and the mean BMI \pm $\mathrm{SD}$ was $24.65 \pm 4.93$ (Table 1). The distribution of BMI groups in the study population suggests that $6 \%$ were underweight, $56 \%$ were with normal weight while $22 \%$ had overweight and $16 \%$ were obese.

The incidence of different types of renal calculi among males and females and their BMI category depicts that uric acid renal stones are more in males when compare with females having more of calcium and magnesium calculi ( Table 2). Also when BMI is considered obese population are equal in both male and female in contrast the underweight male population also have equal chance of getting renal calculi, but statistically there is no significant difference.

Fig 1 represents the different types of renal calculi profile of the study population. Out of the four types of reported calculi, the most common was Calcium oxalates stones $(46 \%)$ which followed by uric acid stones (32\%) magnesium stones (14\%) while phosphate stones was responsible for $8 \%$ of renal calculi. The Fig 2 gender wise suggests females suffer higher from phosphates and calcium oxalates stones while males suffer more from uric acid calculi. However the differences were statistically not significant. 
The risk factors associated with renal calculi are detailed in as Fig 3 presents the renal calculi profile of the study population across various risk factors. Calcium oxalates $(34.8 \%)$, uric acid $(25 \%)$ and magnesium $(42.9 \%)$ were the most common cause of renal calculi among hypertensive patients, where as phosphate $(25 \%)$ and magnesium (28.6) seems to be the major reason in diabetic patients.

Table 3 presents physical activity and renal calculi profile higher physical activity can specially play a positive role in reducing the risk of uric acid calculi. In our study the patients doing moderate activity less than 150minutes per week shows high incidence of renal calculi like calcium oxalate and uric acid when compare to samples performing physical activity more than 150 minutes per week.

Table 4 definitely suggests high fluid intake is associated significantly with renal calculi of all types except for uric acid calculi. As for uric acid calculi the intake of animal protein-rich diet was associated with the highest excretion of undissociated uric acid due to the reduction in urinary $\mathrm{pH}$ also increases the purine content of blood resulting in uric acid stones, but, not for calcium oxalate or calcium phosphate stones [33]. Thus fluid intake is not directly related with uric acid calculi. Table 4 also suggests a possible association between less fluid intake and formation of renal calculi. The samples whose fluid intake was less than 1 litre have $100 \%$ chances to get phosphate and magnesium calculi. But whose consumption of fluid was more than 1 litre have equal chances of getting uric acid calculi. However, there was no significant difference because of less number of samples. In addition almost all the patients complained about urinary tract infections. Table 5 analyse the relationship between obesity and renal calculi and the association is not statistically significant in the study population. But there are trends that the obese samples are much prone to renal calculi.

Table 6 presents the signs and symptoms of renal calculi in the study population. Over all $81.5 \%$ were complaining about the pain in the low back, groin and abdomen whose daily intake of fluids was less than 1 litre also $78.3 \%$ of patients felt pain during urination. In contrast, the patients whose intake of fluids is more than 1 litre, only $18.5 \%$ complains of pain in the low back, groin and abdomen and nearly $22 \%$ complains of pain during urination. Calcium oxalates, uric acid and magnesium renal calculi results in a major symptom of pain during urination followed by the pain in the low back, groin and abdomen while phosphates calculi seems to result more in bladder pain according to the results of the study (data not presented).

\section{Tables And Figures}

Table: 1 Demographic And Anthropometric Profile Of The Study Population

\begin{tabular}{lrrrrr}
\hline Variables & Minimum & Maximum & Mean & Std. Deviation \\
\hline Age $($ years) & 16 & 90 & 42.20 & 19.41 \\
Height $(\mathbf{c m})$ & 150 & 187 & 163.90 & 9.64 \\
Weight $(\mathrm{kg})$ & 45 & 108 & 66.26 & 14.33 \\
BMI $\left(\mathrm{kg} / \mathrm{m}^{2}\right)$ & 16.5 & 38.7 & 24.65 & 4.93 \\
\hline
\end{tabular}

Table: 2 Gender wise Profile of the Study Population (\%)

\begin{tabular}{|c|c|c|c|}
\hline \multicolumn{2}{|l|}{ Variables } & \multicolumn{2}{|c|}{ Gender (\%) } \\
\hline & & \multirow{2}{*}{$\begin{array}{l}\text { Male } \\
43.5\end{array}$} & \multirow{2}{*}{$\begin{array}{r}\text { Female } \\
56.5\end{array}$} \\
\hline Type of Calculi & Calcium oxalate & & \\
\hline & Uric acid & 62.5 & 37.5 \\
\hline & Phosphate & 25.0 & 75.0 \\
\hline & Magnesium & 57.1 & 42.9 \\
\hline \multirow[t]{4}{*}{ BMI Groups } & Underweight & 66.7 & 33.3 \\
\hline & Normal BMI & 42.9 & 57.1 \\
\hline & Overweight & 63.6 & 33.4 \\
\hline & Obese & 50.0 & 50.0 \\
\hline
\end{tabular}

Figure:1 Prevalence of Renal Calculi in the study population (\%)

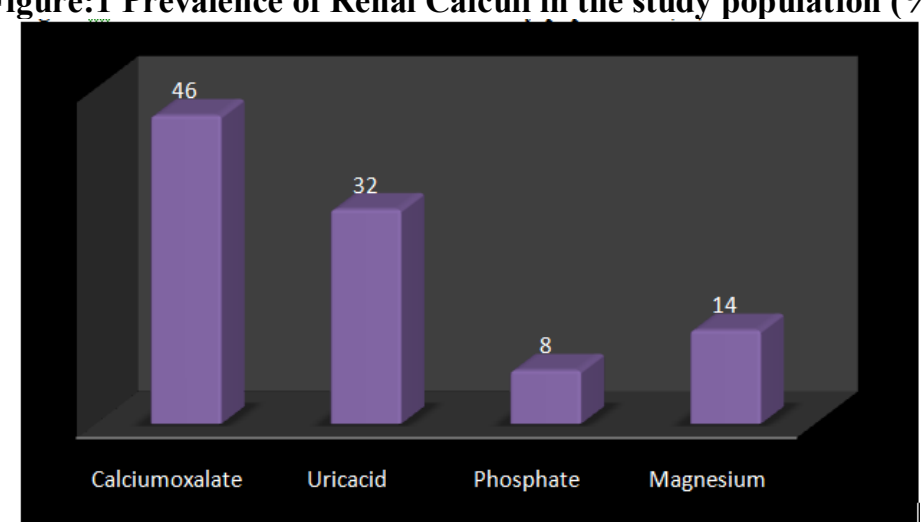


Figure:2 Gender wise Renal Calculi Profile of the Study Population (\%)

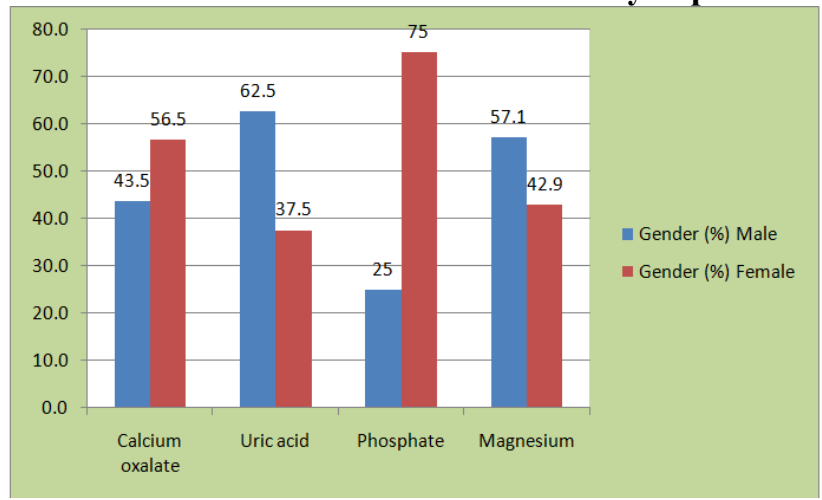

Figure: 3 Co-morbidities and Renal Calculi Profile of the Study Population (\%)

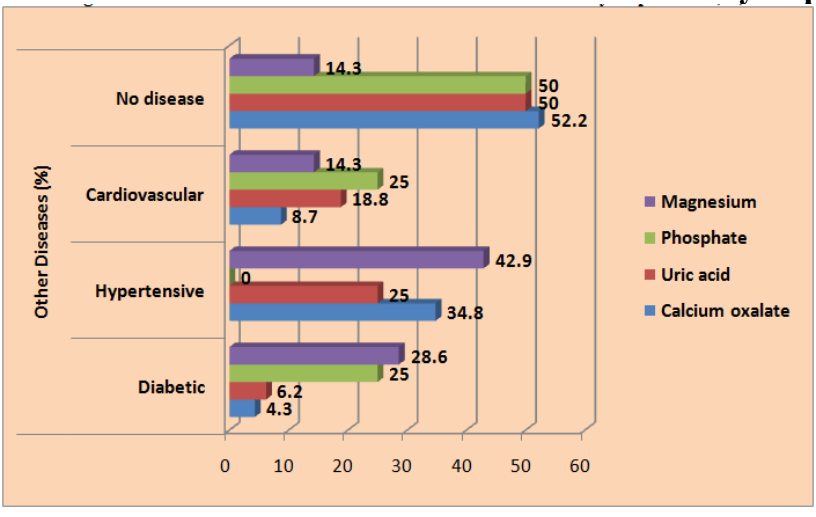

Table:3 Physical Activity and Renal Calculi Profile of the Study Population (\%)

\begin{tabular}{|c|c|c|c|}
\hline \multirow[t]{2}{*}{ Type of Calculi } & \multicolumn{2}{|c|}{ Physical Activity } & \multirow[t]{2}{*}{ Chi-Square } \\
\hline & $\begin{array}{c}\leq 150 \text { minutes per } \\
\text { week }\end{array}$ & $\begin{array}{c}\geq 150 \text { minutes per } \\
\text { week }\end{array}$ & \\
\hline \multirow{4}{*}{$\begin{array}{l}\text { Calcium oxalate } \\
\text { Uric acid } \\
\text { Phosphate } \\
\text { Magnesium }\end{array}$} & 74 & 26 & \multirow{4}{*}{$\begin{array}{c}4.816 \\
(p=0.186)\end{array}$} \\
\hline & 93.8 & 6.2 & \\
\hline & 50.0 & 50.0 & \\
\hline & 85.7 & 14.3 & \\
\hline
\end{tabular}

Table:4 Fluid intake and Renal Calculi Profile of the Study Population (\%)

\begin{tabular}{|l|c|c|c|}
\hline \multirow{2}{*}{ Type of Calculi } & \multicolumn{2}{|c|}{ Fluid Intake } & Chi- Square \\
\cline { 2 - 3 } & $\leq \mathbf{1 . 0 l i t r e s ~ p e r ~ d a y ~}$ & $\mathbf{2 1 . 0 l i t r e s ~ p e r ~ d a y ~}$ & $\mathbf{9 . 0 8 6} *$ \\
$\mathbf{( p = 0 . 0 2 3 )}$
\end{tabular}

Table:5 BMI and Renal Calculi Profile of the Study Population (\%)

\begin{tabular}{|c|c|c|c|c|c|}
\hline \multirow[t]{2}{*}{ Type of Calculi } & \multicolumn{4}{|c|}{ BMI Groups } & \multirow[t]{2}{*}{ Chi-Square } \\
\hline & Underweight & Normal & Overweight & Obese & \\
\hline Calcium oxalate & 13.0 & 56.5 & 17.4 & 13.0 & \multirow{4}{*}{$\begin{array}{c}8.066 \\
(p=0.528)\end{array}$} \\
\hline Uric acid & 0.0 & 50.0 & 37.5 & 12.5 & \\
\hline Phosphate & 0.0 & 75.0 & 0.0 & 25.0 & \\
\hline Magnesium & 0.0 & 57.1 & 14.3 & 28.6 & \\
\hline
\end{tabular}

Table:6 Signs and Symptoms of renal calculi in the study population (\%)

\begin{tabular}{|c|c|c|c|}
\hline \multirow{2}{*}{$\begin{array}{l}\text { Signs and } \\
\text { symptoms }\end{array}$} & \multicolumn{2}{|c|}{ Fluid Intake } & Chi- Square \\
\hline & $\leq 1.0$ litres per day & $\geq 1.0$ litres per day & \multirow{3}{*}{$\begin{array}{c}0.881 \\
(p=0.777)\end{array}$} \\
\hline $\begin{array}{l}\text { Pain-Low } \\
\text { back/Groin/Abdo } \\
\text { men }\end{array}$ & 81.5 & 18.5 & \\
\hline $\begin{array}{l}\text { Pain during } \\
\text { Urination }\end{array}$ & 78.3 & 21.7 & \\
\hline
\end{tabular}




\section{Discussion}

Kidney stones result when urine becomes too concentrated and substances in the urine crystallize to form stones. The most common cause of kidney stones is not only drinking enough water but excessive intake of animal protein and vegetables rich in minerals. Kidney stones have become increasingly prevalent in the developed countries over the past 100 years. The incidence of urolithiasis in a population depends on the geographical area, racial distribution, socio-economic status and dietary habits. During the past decades, these factors have changed affecting the incidence and also the chemical composition of calculi. The identification of the calculi composition enables both clinical management with possibility of good treatment, lower (decreased) cost and a better quality of life; and better understanding of physicochemical principles underlying the formation.

The purpose of the study is to assess the different types of renal calculi among the samples and to correlate their health status and their fluid intake. In our study both men and women in their adult age ranging from 25 years to 45 years are very much prone to renal calculi. Nearly $38 \%$ of the study population was above normal weight with less physical activity. The most common stone composition was calcium oxalate followed by uric acid, magnesium and phosphorus calculi while cystine stones were absent. These results are in agreement with previous Saudi studies [28]. In our study, calcium oxalate stones were found in $46 \%$ of all cases followed by uric acid stones $32 \%$. This rate is comparable to those reported in a recent study [29]. The main reason from the dietary point of view is that meat (from camel and lamp) is the staple food of Saudi Arabians. The purine content of blood increases with increase consumption of meat and meat products resulting in the formation of stones like uric acid.

Diabetic and Hypertension were the other risk factors closely associated with renal calculi in the study population. Those with hypertension are more likely to develop kidney stones, especially when they are overweight.[30,31].

Obesity is another risk factor which contributes to kidney stones. Since body fat is hydrophobic, the proportion of body water decreases with increasing obesity, which can lead to dehydration [32]. The associated changes in body composition pose biophysical challenges associated with disturbed thermo genesis and dehydration. In addition, if the fluid intake is not balanced with dehydration it will lead to concentrated urine resulting in stone formation. But in our study trends are there when overweight and obesity are considered as the risk factors.

Finally fluid intake seems to be highly correlating factor with calculi prevalence with patients complaining of urinary infections correlated with severe pain in the back, groin and lower abdomen. Since this study was done during winter season and Hail being a place with high altitude and severe winters, there was every possibility for patients to drink less water and as a consequence suffer from aggravating symptoms of calculi.

It is well understood that lifestyle of the patients has to be improved in all aspects like changing their dietary habits by including more of fruits, vegetables, high fiber foods, more fluid intake, and physical activity. A coordinated effort has to be taken to reduce the tendency of renal calculi formation and to promote healthy eating habits among the people of Saudi Arabia.

\section{Conclusion}

In conclusion, although data on kidney stone disease in Saudi Arabia is scarce, our data provide an idea about its epidemiologic characteristics. More elaborate studies need to be carried out in large scale to analyze the different types of renal calculi, its composition and its association with dietary, genetic and environmental factors. Here are the possibilities that may explain our findings. First, Calcium oxalate stones remain the most frequent components followed immediately by uric acid. Second, gender differences are reported with males having higher prevalence of uric acid calculi while females suffering from calcium oxalate calculi. Third we found that fluid intake is significantly associated with calculi prevalence. Analysis of these data showed that urinary stones seen in Hail patients are tending to evolve in the same direction as stones seen in patients in industrialized countries. Management of renal calculi can be achieved by focusing on proper diet, exercise and adequate fluid intake. A multidisciplinary approach should be adopted like changing their lifestyle, dietary intervention on large scale and health education in this regard may be helpful as a preventive measure to overcome the problem.

\section{References}

[1]. Preminger, GM (2007). "Chapter 148: stones in the urinary tract". In Cutler, RE. The Merck Manual of Medical Information Home Edition (3rd ed.). Whitehouse Station, New Jersey: Merck Sharp and Dohme Corporation.

[2]. Wolf Jr. JS (2011). "Background "Nephrolithiasis. New York: WebMD. Retrieved 2011-07-27.

[3]. Shokouhi B, Gasemi K, Norizadeh E. Chemical composition and epidemiological risk factors of urolithiasis in Ardabil Iran. Research Journal of Biological Sciences 2008; 3(6): 620-626,

[4]. Collele J, Kochis E, Galli B, Munver R. Urolithiasis/Nephrolithiasis: What's it all about? Urologic Nursing. 2005; 25(6): 427-48 
[5]. Vinay K, K. Abul A.N Fausto and N.R. Mitchell, 2007. Renal stones in: Robbins Basic Pathology. 8th Edition. Saunders Company, pp 571-572.

[6]. Abbagani S, Gundimeda SD, Varre S, Ponnala D, Mundluru HP. Kidney Stone Disease: Etiology and Evaluation. IJABPT. MayJuly $2010 ; 1(1): 175-182$.

[7]. Hiatt RA, Dales LG, Friedman GD, Hunkeler EM. Frequency of urolithiasis in a prepaid medical care program. Am J Epidemiol. 1982;115:255-265.

[8]. Stamatelou KK, Francis ME, Jones CA, et al. Time trends in reported prevalence of kidney stones in the United States: 1976-1994. Kidney Int. 2003;63:1817-1823.

[9]. Soucie JM, Thun MJ, Coates RJ, et al. Demographic and geographic variability of kidney stones in the United States. Kidney Int. 1994;46:893-899.

[10]. Sánchez-Martín FM, Millán Rodríguez F, Esquena Fernández S, et al. Incidence and prevalence of published studies about urolithiasis in Spain: a review [article in Spanish] Actas Urol Esp. 2007;31:511-520.

[11]. Amato M, Lusini ML, Nelli F. Epidemiology of nephrolithiasis today. Urol Int. 2004;72(suppl 1):1-5.

[12]. Serio A, Fraioli A. Epidemiology of nephrolithiasis. Nephron. 1999;81(suppl 1):26-30.

[13]. Hesse A, Brändle E, Wilbert D, et al. Study on the prevalence and incidence of urolithiasis in Germany comparing the years 1979 vs. 2000. Eur Urol. 2003;44:709-713.

[14]. Ramello A, Vitale C, Marangella M (2000) Epidemiology of nephrolithiasis. J Nephrology 13:S65-S70.

[15]. Robertson WG, Hughes H (1994) Epidemiology of urinary stone disease in Saudi Arabia. In: Ryall R, Bais R, Marshall VR, Rofe AM, Smith LH, Walker VR (eds) Urolithiasis 2. Plenum Press, New York London, pp 453-455.

[16]. Bihl G, Meyers A. Recurrent renal stone disease--advances in Pathogenesis and clinical management. Lancet. 2001; 358 (9282): 651-6.

[17]. Devuyst O.Pirson Y. Genetics of hypercalciuric stone forming diseases. Kidney International .2007; 72 (9): 1065-72.

[18]. Prié D, Friedlander G. Genetic Causes of Renal Lithiasis.International Bone \& Mineral Society (IBMS). $2009 ; 357-67$. W.G.Robertson, Epidemiology of urinary stone disease, Urological Research Dec 1990, Volume 18, issue 1, pps3-s8.

[19]. Al-Khader, AA: Impact of diabetes in renal diseases in Saudi Arabia. Nephrol Dial Transplant 2001 16:2132-2135.

[20]. Akel, M, Hamadeh, G: Quality of diabetes care in a university health center in Lebanon. Int J Qual Health Care 1999 11:517-521.

[21]. El-Reshaid, K, Johny, KV, Sugathan, TN, et al: End-stage renal disease and renal replacement therapy in Kuwait-epidemiological profile over the past 4 1/2 years. Nephrol Dial Transplant 1994 9:532-538.

[22]. Barsoum, R: Nephrology in Egypt: A Forecast of the Upcoming Century. Available at: http://www.health.egnet.net/health/esn/forecast.html. Accessed 2003.

[23]. Al-Nuaim, A, Bamgboye, E, Al-Herbish, A: The pattern of growth and obesity in Saudi Arabian school children. Int J Obes Relat Metab Disord 1996 20:1000-1005.

[24]. Al-Mahroos, F, Al-Roomi, K: Overweight and obesity in the Arabian Peninsula: An overview. J R Soc Health 1999 119:251-253.

[25]. Al-Almaie SM. Prevalence of obesity and overweight among Saudi adolescents in Eastern Saudi Arabia. Saudi Med J. 2005; 26: $607-11$.

[26]. Over weight and Obesity. http://www.who.int/mediacentre/factsheets/fs311/en/ Accessed on 18th, January, 2012

[27]. Khan AS, Rai ME, Gandapur, Pervaiz A, Shah AH, Hussain AA, Siddiq M. Epidemiological risk factors and composition of urinary stones in Riyadh Saudi Arabia. J Ayub Med Coll Abbottabad. 2004 Jul-Sep;16(3):56-8.

[28]. Silva SF, Matos DC, Silva SL, Daher Ede F, Campos Hde H, Silva CA. Chemical and morphological analysis of kidney stones: a double-blind comparative study. Acta Cir Bras. 2010;25:444-448.

[29]. Borghi L, Meschi T, Guerra A et al. Essential arterial hypertension and stone disease. Kidney Int. 1999; 55: 2397-406.

[30]. Cappuccio FP, Siani A, Barba G et al. A prospective study of hypertension and the incidence of kidney stones in men. J. Hypertens. 1999; 17: 1017-22.

[31]. Batmanghelidj F, Kohlstadt I. Water: a driving force in the musculoskeletal system. In: Scientific Evidence for Musculoskeletal, Bariatric and Sports Nutrition. Boca Raton, Fla.: Taylor \& Francis; 2006:127-135.

[32]. Breslau NA, Brinkley L, Hill KD, Pak CY. Center in Mineral Metabolism and Clinical Research, Department of Internal Medicine, Dallas, Texas "Relationship of animal protein-rich diet to kidney stone formation and calcium metabolism",PubMed1988 Jan;66(1):140-6. 